\title{
Shaking table tests on shallow foundations
}

\author{
J. Estaire \& V. Cuéllar \\ Laboratorio de Geotecnia, CEDEX, $M^{o}$ de Fomento, Madrid, Spain
}

\begin{abstract}
In this paper the results of shaking table tests on shallow foundations, using dry Hostun RF sand, are presented. These tests were performed in a six-degree of freedom seismic simulator formed by $3 \mathrm{~m}$ long square table, able to move $10 \mathrm{t}$ mass with up to $1-\mathrm{g}$ accelerations. On that simulator a rigid box of great dimensions ( $3 \mathrm{~m}$ long, 1,1 $\mathrm{m}$ wide and 1,2 $\mathrm{m}$ high) was placed and filled with some $6 \mathrm{t}$ of sand. During the filling of the box, some accelerometers were installed inside the sand to measure accelerations suffered by the granular deposit. The shallow foundations were modelled with three metallic blocks that transmitted different loads to the ground. The tests were designed taking into account the usual scale factors.

In the thirty tests performed, the shaking table imposed a wavy acceleration at the bottom of the box with different amplitudes and frequencies.

The result analysis was focused on the amplification of acceleration during its propagation in vertical direction through the sand deposit and the vertical and horizontal movements of the foundation blocks during the dynamic excitation.

Keywords: model test, shallow foundations, earthquake resistant, sand, settlement.
\end{abstract}

\section{Introduction}

Earthquakes are still nowadays natural phenomena of a great destructive potential, so there is a great interest in achieving a better knowledge of the behaviour of soils and the structures founded on them under dynamic conditions.

Shallow foundations have had a seismic behaviour that can be qualified as good and adequate, so they have not received much attention in the past. However, failure cases reported in some buildings in Ciudad de Mexico, founded on soft clay, during the Michoacán earthquake in 1985, Romo and Auvinet [1], 
changed this way of thinking and made it necessary to consider the problem of the dynamic behaviour of shallow foundations.

\section{Testing method followed}

The reduced scale tests were conducted in the six-degree of freedom shaking table belonging to CEDEX (Madrid, Spain). This seismic simulator is formed by a $3 \mathrm{~m}$ long square table moved by several actuators whose movements are servocontrolled, Navarro [2]. On this shaking table a rigid box wax installed, consisting of a metallic structure with lateral walls, made of $5 \mathrm{~mm}$ wide transparent metacrilate. The box was $3 \mathrm{~m}$ long, 1,1 $\mathrm{m}$ wide and 1,2 $\mathrm{m}$ high and had a capacity of $4 \mathrm{~m}^{3}$. The weight of the empty structure was $380 \mathrm{~kg}$ and filled with around $6 \mathrm{t}$ of Hostun RF sand, Flavigny et al [3].

This sand is a uniform sand of medium size, as the diameter of its grains is between 0,65 and $0,16 \mathrm{~mm}$, the mean diameter $\left(D_{50}\right)$ is about $0,35 \mathrm{~mm}$ and the coefficient of uniformity $\left(\mathrm{C}_{\mathrm{u}}=\mathrm{D}_{60} / \mathrm{D}_{10}\right)$ is around 1,8 . The maximum and minimum densities obtained in laboratory were $15,68 \mathrm{kN} / \mathrm{m}^{3}$ and $12,65 \mathrm{kN} / \mathrm{m}^{3}$.

The sand was poured through a 50-litre hopper in $20 \mathrm{~cm}$ layers. Once each layer was levelled, the whole system was vibrated during one minute with acceleration at the base of the table of $40 \mathrm{~Hz}$ frequency and $0,25 \mathrm{~g}$ amplitude. The sand was thus laid with an average relative density of $90 \%$. Above the different sand layers, a one $\mathrm{cm}$ thick layer of coloured sand was poured beside the transparent metacrilate walls to control the evolution of sand settlements in depth. Figure 1 shows the box filled with sand situated on the shaking table, with the displacement transducers situated on the surface.

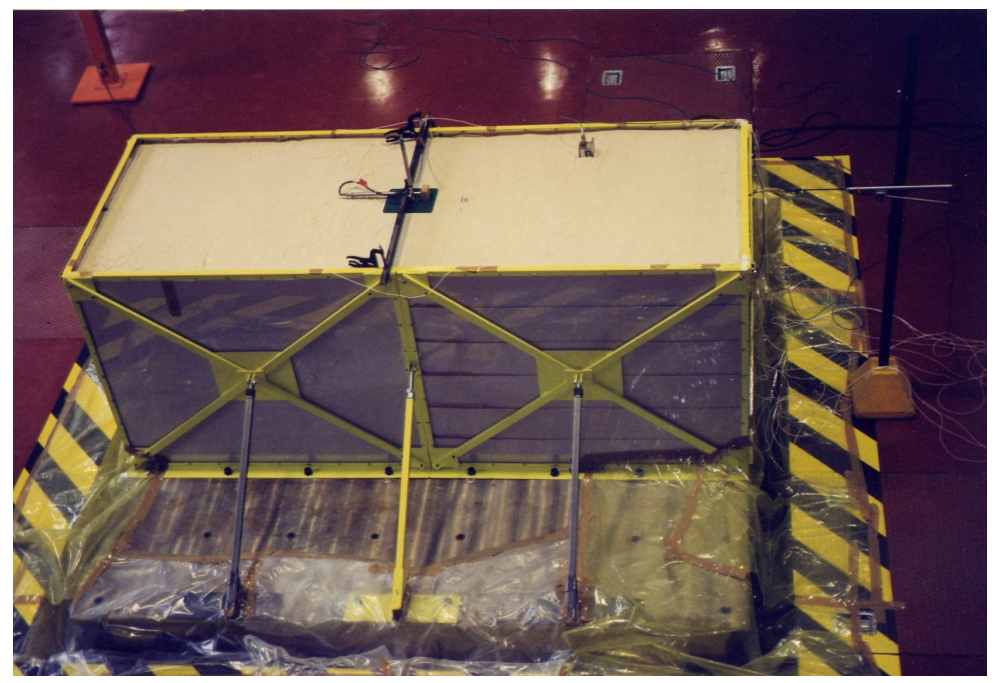

Figure 1: Photograph of the box, filled with sand, on the shaking table. 
The situation of the measurement apparatus can be seen in Figure 2. Some LVDT transducers were installed on the metallic blocks, which simulated shallow foundations, to measure their vertical and horizontal displacements. The horizontal movement of the whole box was also controlled. The vertical movement of the sand deposit, at a point away from the influence zone of the foundation, was measured in order to keep a record of the evolution of the density of the sand deposit during the dynamic excitation.

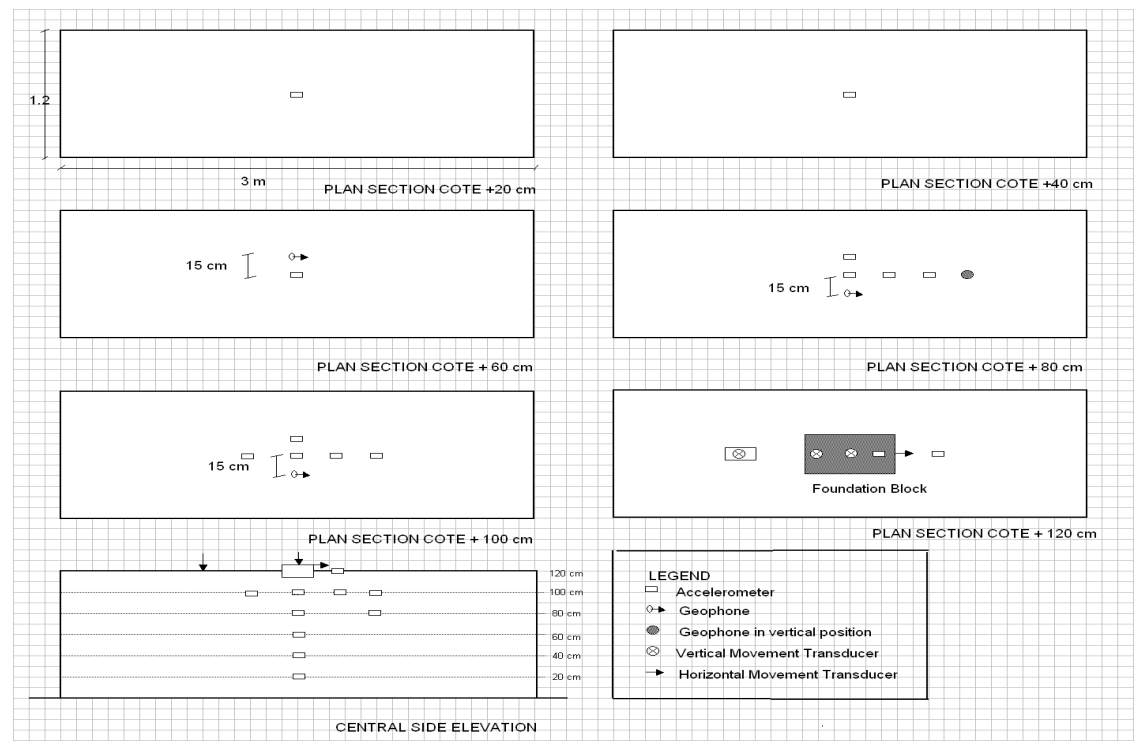

Figure 2: $\quad$ Position of the accelerometers and displacement transducers.

\section{Tests performed}

The tests were performed placing on top of the sand deposit a metallic block of $25 \mathrm{~cm}$ long, $20 \mathrm{~cm}$ wide and $15 \mathrm{~cm}$ high, buried $5 \mathrm{~cm}$ deep, which simulated a shallow foundation. Three metallic blocks (named Z-A, Z-B, Z-C) weighting 1,5; 20 and $40 \mathrm{~kg}$, respectively, were used.

The foundation blocks used in the tests and the sand deposit that they were placed on were designed to simulate real situations of shallow foundations resting on dry sandy layers. According to the scale factors applicable to the tests, Iai [4], the geometry and the loads of these tests make it possible to simulate a great number of real cases. For instance, if a scale factor of 10 is used, the resultant foundation dimensions $(2,5 \times 2,0 \times 1,5 \mathrm{~m})$ and the vertical stresses transmitted to the ground $(80 \mathrm{kPa})$ by the heaviest block are usual values in daily practice. The interpretation of the test results must be done taking into account the corresponding scale factor to displacements, velocities and accelerations. 
With the measurement system implemented in the box, 30 tests were performed, in which, for each of the three foundation blocks, the frequency of the imposed signal of accelerations in the base of the box $(5$ and $10 \mathrm{~Hz})$ and the amplitude $(0,1-0,2-0,35-0,5$ and $0,6 \mathrm{~g})$ were changed.

It was decided to perform tests with amplitudes of imposed acceleration superior to $0,35 \mathrm{~g}$, which is the limit value derived from the fluidisation theory by Richards et al [5] for fine granular material and a value scarcely exceeded in similar tests performed on shaking tables by different research groups as Fukutake et al [6], Taylor [7], Shamoto et al [8] and Maugeri et al [9]. The aim of the tests performed with high accelerations was, on one hand, to test the validity of such theory and, on another hand, to analyse the behaviour of a sand deposit in such a "fluidisation" situation, when sand stops behaving as a frictional material to begin showing a behaviour similar to a fluid.

The tests lasted 20 seconds, so 100 cycles were imposed, in the tests with a frequency of $5 \mathrm{~Hz}$, and 200 cycles in those with $10 \mathrm{~Hz}$ of frequency. Figure 3 shows one of the signals, in terms of accelerations, imposed on the shaking table to perform the tests. It can be seen that, at the beginning and at the end of the imposed signal, the acceleration increases and decreases, respectively, in a ramp during two cycles, to make easier the task of the shaking table actuators.

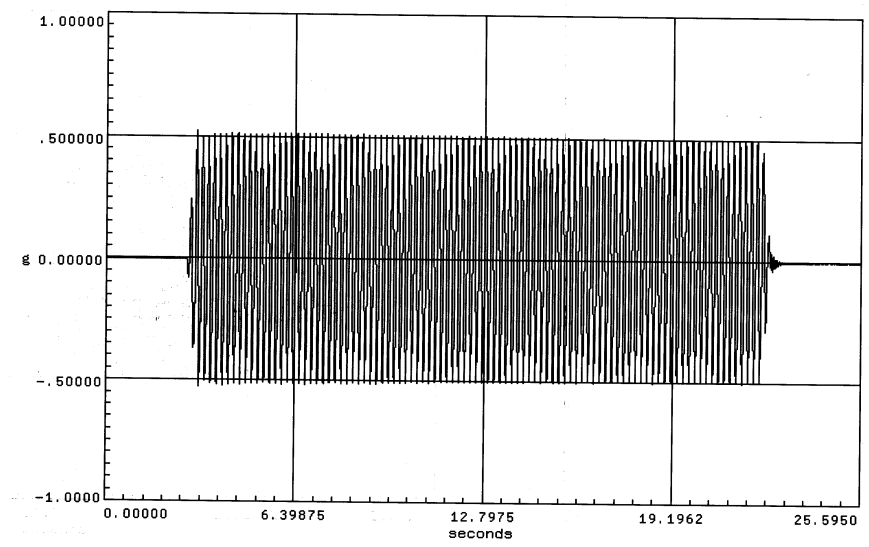

Figure 3: $\quad$ Signal imposed by the shaking table at the base of the box.

\section{Results obtained}

\subsection{Amplification of horizontal acceleration in vertical direction}

This section studies the amplification of horizontal accelerations on the shaking table, during its vertical propagation until reaching the top sand surface and the influence of the presence of the metallic blocks. Figure 4 shows the records of horizontal accelerations measured in the box base and near the surface. 


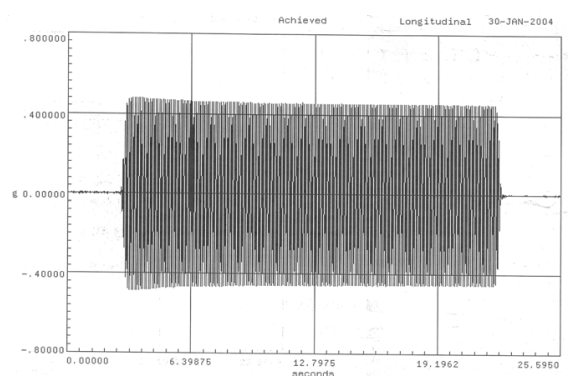

a) Box base

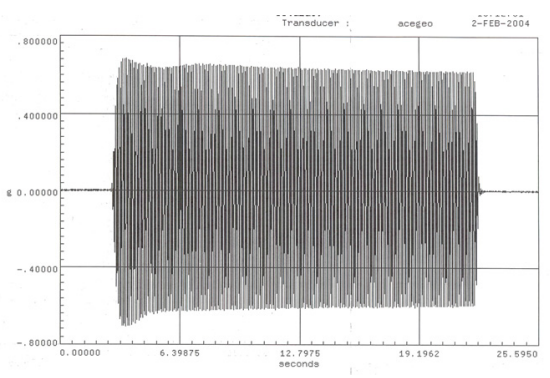

b) Near the surface

Figure 4: Records of horizontal accelerations at different depths in the box.

The average values of the measured acceleration amplification have been represented for each group of tests performed in Figure 5. The average curve obtained in free field tests performed in the same conditions, Estaire and Cuéllar [10], was also included. The amplification was quantified in percentage value, comparing the maximum amplitude measured at each depth with the amplitude of the acceleration imposed by the shaking table at the base of the box.

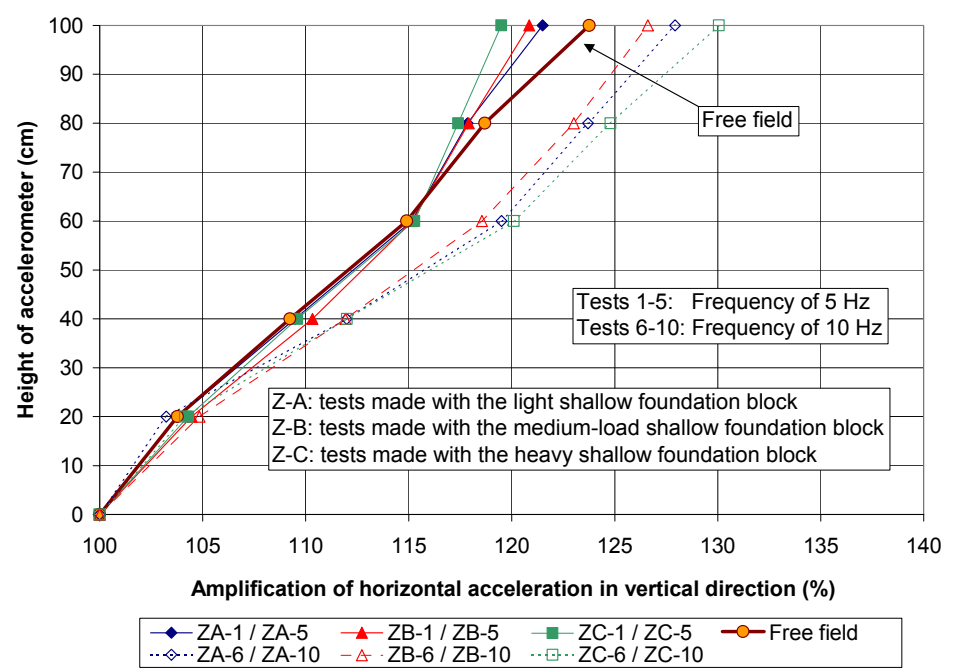

Figure 5: Average acceleration amplification in vertical direction.

The principal aspects that can be highlighted from the results are:

a.- In all the tests, the acceleration amplitude increases when the signal moves vertically along the sand.

b.- Larger amplifications were obtained in the tests performed with higher frequency. This difference is more noticeable as the acceleration amplitude imposed at the bottom of the box increases. 
c.- The amplification measured in the accelerometers situated at $100 \mathrm{~cm}$ high is lower in the tests performed with a foundation block, if compared with the free field tests performed with the same frequency signal of $5 \mathrm{~Hz}$. This difference increases, as the load imposed by the foundation block is greater. This aspect can be analysed more carefully in Figure 6, in which the amplification measured in the accelerometer nearest to the foundation block was represented for all the tests.

The analysis of Figure 6 makes it possible to highlight the following experimental aspects:

a.- In all the cases, independently of the frequency, the signal amplification increases parallel to the increase in the amplitude of the acceleration signal imposed. This fact can be checked through the parabolic curves that adjust the experimental results.

$$
\begin{aligned}
& \text { Amplification }_{(\text {in } \%)}=115+100 . a_{(i n g)}^{3,5} \ldots . . \text { for } 5 \mathrm{~Hz} \text { frequency } \\
& \text { Amplification }_{(\text {in } \%)}=115+100 . a_{(i n g)}^{2} \ldots . . \text { for } 10 \mathrm{~Hz} \text { frequency }
\end{aligned}
$$

b.- In all the cases, the amplification is greater in the tests performed with the acceleration signal of highest frequency $(10 \mathrm{~Hz})$. This greater amplification can be due to the fact that frequency of $10 \mathrm{~Hz}$ is nearer to the sand deposit natural frequency, which can be quantified in about $40 \mathrm{~Hz}$, taking into account that the shear wave propagation velocity in vertical direction is about $190 \mathrm{~m} / \mathrm{s}$, as interpreted from shear propagation test results.

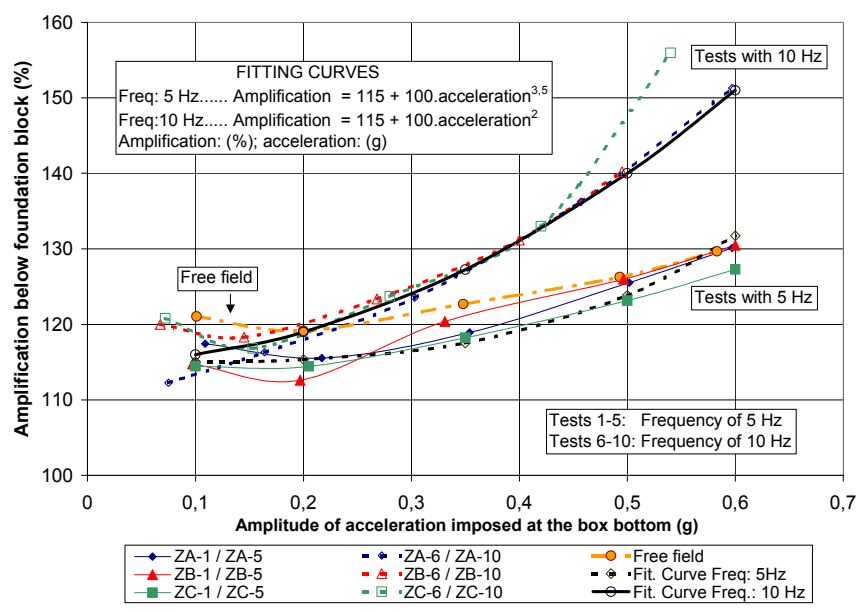

Figure 6: Amplification in the ground below the foundation block.

c.- Furthermore, it can be seen that the difference between the results obtained with the two frequencies $(5$ and $10 \mathrm{~Hz}$ ) is greater when the amplitude of the imposed acceleration signal increases.

d.- The difference in the amplification measured below the foundation block, between the free field situations and when a block is placed on 
top, decreases when the amplitude of the imposed acceleration signal increases.

\subsection{Vertical movements of foundation blocks}

The vertical movements of the shallow foundations were also analysed. Figure 7 shows two of the vertical movement records, representatives of all the tests. In some of the tests there was almost no remaining settlement, as all the vertical movement had a wavy recoverable nature. On the contrary, in other tests the settlement experienced by the foundation block when the test finished can be clearly seen, although during the dynamic excitation part of the vertical movement was wavy and recoverable.

The results obtained in all the tests have been represented in Figures 8 and 9. The curves that best fitted the results have been also included in both figures.
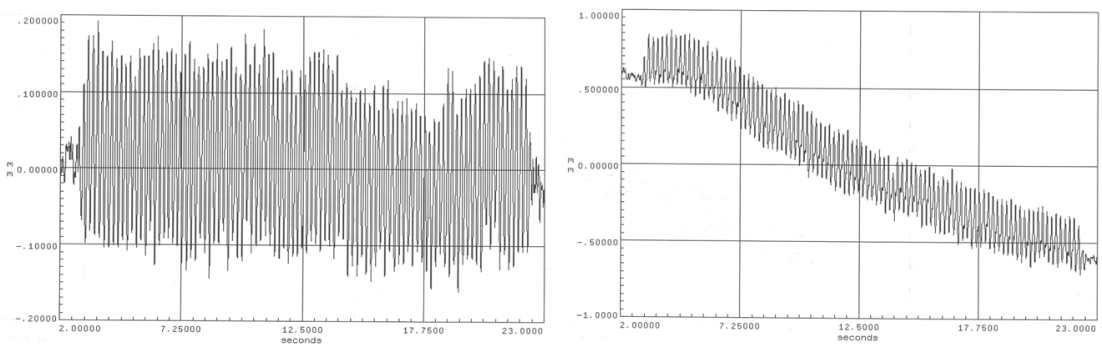

Figure 7: Vertical movement records of the foundation blocks.

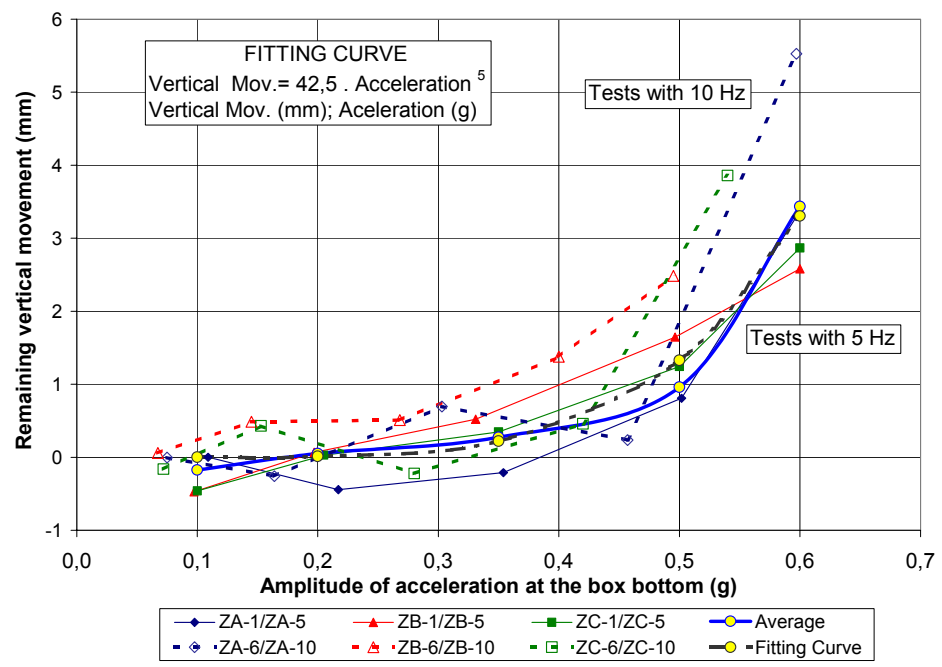

Figure 8: Remaining vertical movement measured in the foundation blocks. 


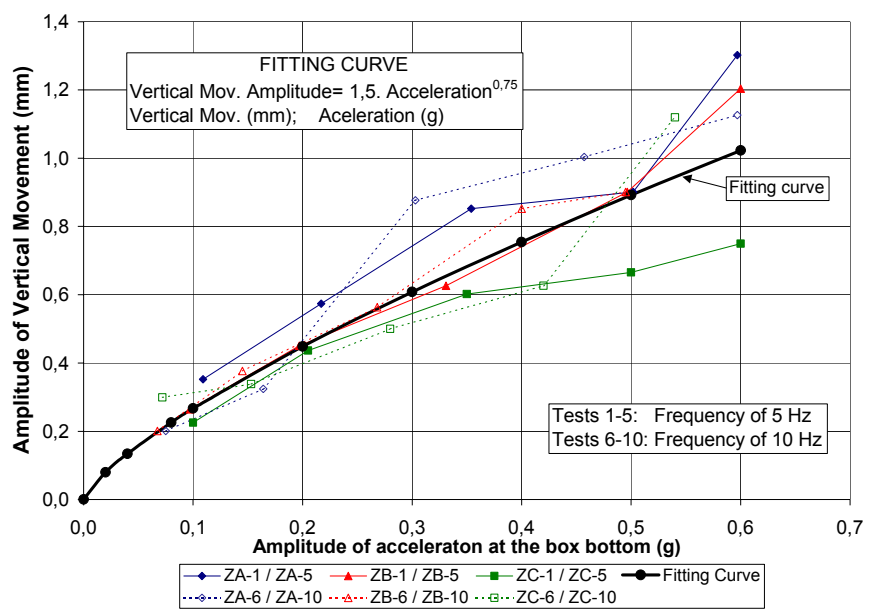

Figure 9: Average amplitude of the vertical movement of the blocks.

The analysis of the vertical movements obtained in the tests makes it possible to state the following:

a.- In all the tests with an imposed acceleration amplitude inferior to $0,35 \mathrm{~g}$, the observed behaviour can be qualified as almost elastic: the remaining vertical movements measured were less than $0,7 \mathrm{~mm}$ and the vertical movement amplitude was superior to the vertical remaining movement.

b.- On the contrary, for the greatest amplitudes used in the tests $(0,5$ and $0,6 \mathrm{~g})$ the remaining settlements are bigger: about $2 \mathrm{~mm}$ in the tests made with amplitude of 0,5 and between 2,5 and $5,5 \mathrm{~mm}$, for the tests made with amplitude of $0,6 \mathrm{~g}$. Besides, in these cases, the amplitude of the vertical movement was lower than the remaining settlement.

c.- The measured movements do not allow the establishment of a clear different behaviour in relation to the foundation block load.

d.- The movements measured in the tests performed with the imposed acceleration signal of highest frequency $(10 \mathrm{~Hz})$ are, in general, greater than the ones recorded in $5 \mathrm{~Hz}$ frequency tests.

e.- The vertical movements increases exponentially with the imposed acceleration amplitude, as can be checked numerically with the fitting curve:

f.- $\quad$ The vertical movement amplitude grows parabolically with the imposed acceleration amplitude as is reflected in the fitting curve.

\subsection{Horizontal movements of foundation blocks}

During the tests, the horizontal movement of the foundation blocks in the direction of the imposed acceleration, relative to the box walls, was measured with a displacement transducer. Two of the records of such movements can be 
seen in Figure 10. These two records are representative of the two types of movements obtained in the different tests: those in which the block had a wavy and recoverable horizontal movement and those in which there was a final remaining sliding.

The test results are represented in Figures 11 and 12.

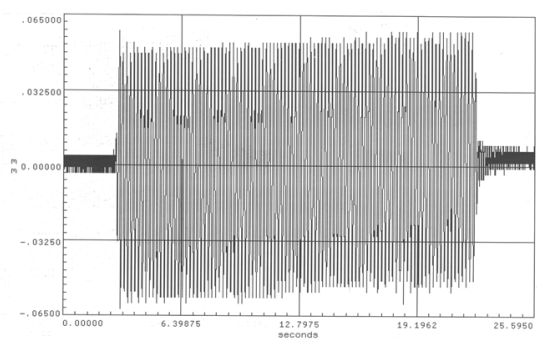

a) No remaining horizontal movement

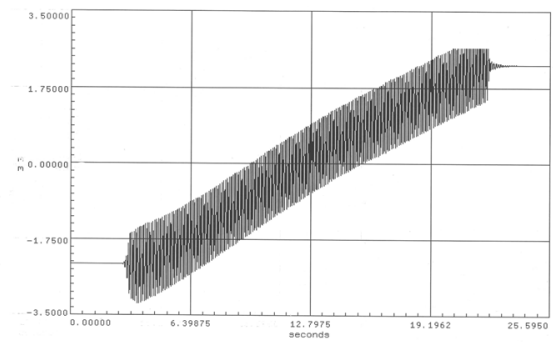

b) Great remaining sliding

Figure 10: Record of relative horizontal movement of the foundation blocks.

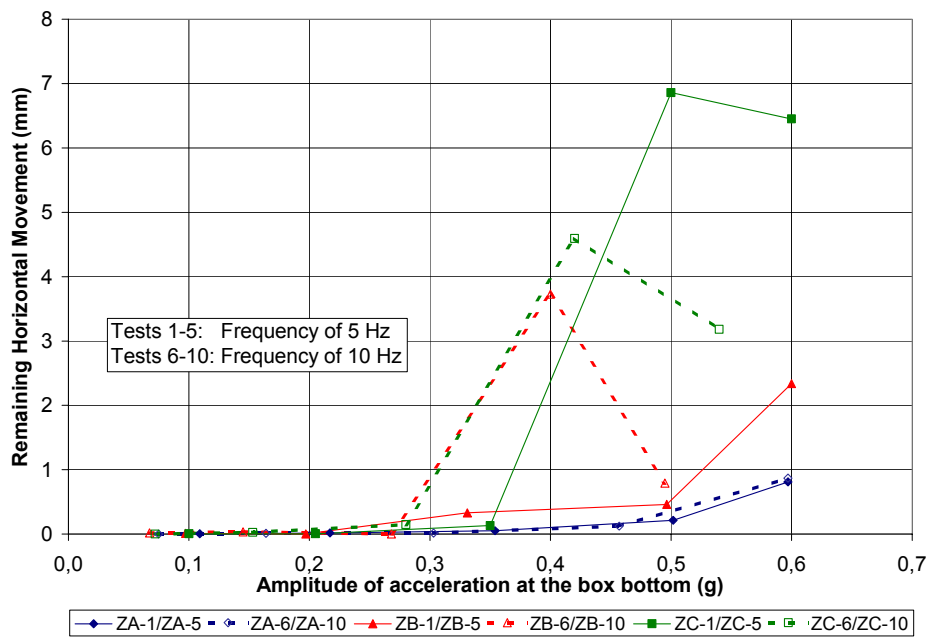

Figure 11: Remaining horizontal movement measured in the foundation blocks.

The following comments can be made as a result of the analysis of the horizontal movement data obtained in the tests:

a.- $\quad$ From a general point of view, the tests made it possible to prove that, in all the cases, the remaining horizontal movement of the foundation blocks, and the amplitude of that movement, increase considerably when the imposed acceleration amplitude is superior to $0,35 \mathrm{~g}$. This value is similar to the one deduced from the "fluidisation theory" by Richards et al [5] for a sandy material with an angle of friction of about $35^{\circ}$. 


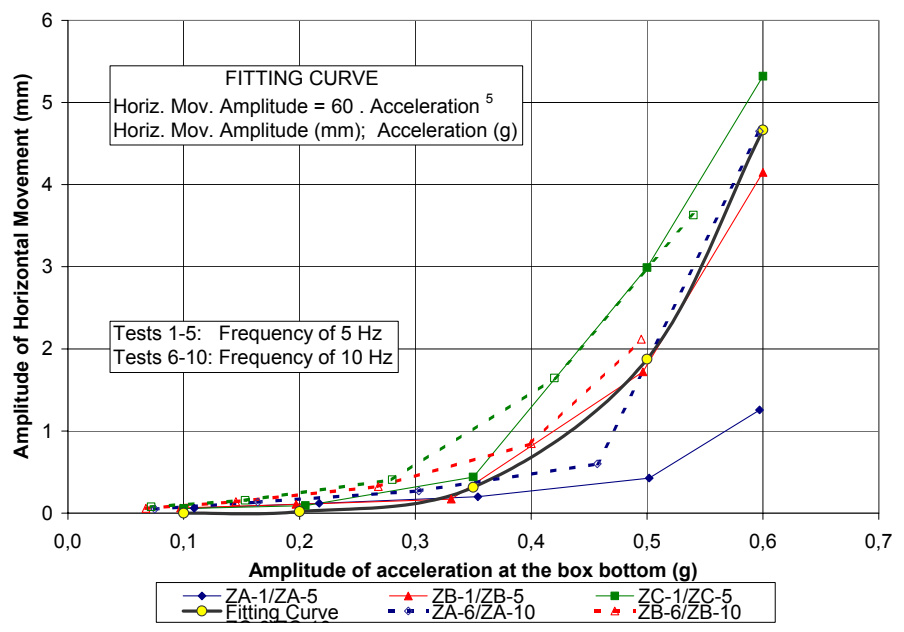

Figure 12: Amplitude of the horizontal movement measured in blocks.

b.- The results seem to indicate that the greater the mass of the foundation block used, the greater the horizontal movement, the other factors being equal.

c.- The horizontal movement amplitude increases exponentially with the amplitude of the acceleration imposed at the bottom of the box.

d.- In all the tests, except in the four with the greatest remaining horizontal movement, the horizontal movement is superior to the value of the remaining sliding of the foundation block. This fact indicates that the nature of the horizontal movement was, in general, wavy, elastic and recoverable.

\section{Conclusions}

a.- There exists a great difference in the acceleration amplifications measured in the tests in relation to the imposed acceleration frequency. The presence of the foundation block modifies the accelerations in the zone of the ground affected by the load.

b.- The measured accelerations seem to indicate that when the imposed acceleration amplitude is either 0,5 or $0,6 \mathrm{~g}$, the general behaviour of the foundation can be considered unstable, as indicated by the fluidisation theory by Richards et al [5].

c.- The values of the remaining vertical movement of the foundation blocks, measured in the tests performed with accelerations of amplitude superior to a certain critical value $(0,35 \mathrm{~g}$, in this case) can be high, even for high relative densities in the foundation ground. In these cases there has been no evidence of additional densification in non-loaded zones. 
d.- This fact indicates that shallow foundations can have settlements incompatible with a good behaviour of the founded structure.

e.- The great remaining horizontal movements when the acceleration amplitude is superior to a certain critical value $(0,35 \mathrm{~g}$, in this case) indicate that shallow foundations can exceed the sliding resistance at its base. In this case, the failure of the foundation can occur due to the corresponding ultimate limit state of sliding, a situation which can be more frequent when the vertical applied loads are low, as in bridge abutments.

\section{Acknowledgements}

The authors wish to acknowledge D. Francisco Navarro and his team for their dedication and effort during the performance of the shaking table tests.

\section{References}

[1] Romo, M. \& Auvinet, G., Seismic Behaviour of Foundations on cohesive soft soils (Chapter III). Recent Advances in Earthquake Eng. and Struct. Dynamics. Ouest Editions, Nantes, pp 311-328, 1992.

[2] Navarro, F., Simulador sísmico de seis grados de libertad. Técnicas de compensación analógicas y numéricas. Ingeniería Civil, 100, 1995.

[3] Flavigny, E., Desrue, S. J. \& Palayer, B., Note technique: le sable d'Hostun R.F. Rev. Franc. Géotech., No 53, pp. 67-70, 1990.

[4] Iai, S. \& Sugano, T., Soil-structure interaction studies through shaking table test. Earthquake Geotech. Eng. Lisboa. Balkema, pp. 927-940, 1999.

[5] Richards, R., Budhu, M. \& Elms, D.G., Seismic Fluidisation and Foundation Behaviour. Second Int. Conf. on Recent Advances in Geotechnical Earthquake Engineering and Soil Dynamics. St. Louis, Missouri, Paper No. 5.11, 1991.

[6] Fututake, K., Ohtsuki, A., Sato, M. \& Shamoto, Y., Analysis of saturated dense sand-structure system and comparison with results from shaking table. Earthq. Eng. and Structural Dynamics, Vol. 19, pp. 977-992, 1990.

[7] Taylor, C.A., Dar, A.R. \& Crewe, A.J., Shaking table modelling of seismic geotechnical problems. $10^{\text {th }}$ Europ. Conf. on Earthq. Eng., 1994.

[8] Shamoto, Y., Sato, M. \& Zhang, J., Simplified estimation of earthquake induced settlements in saturated sand deposits. Soils and Foundations, Vol. 36, No. 1, pp. 39-50. March. 1996.

[9] Maugeri, M., Musumeci, G. \& Novita, D., Shaking table test to failure of a shallow foundation subjected to an eccentric load (Chapter 4). Report No. 6: Soil Dynamics and Foundation Structures. ECOEST2, 2001.

[10] Estaire, J. \& Cuéllar, V., Shaking table dynamic tests of a granular deposit. V ERES, pp. 451-460.Thessaloniki (Greece), May, 2005. 